\title{
Erratum to: Semantic Issues in E-Commerce Systems
}

\author{
Robert Meersman ${ }^{1}$, Karl Aberer ${ }^{2}$, and Tharam Dillon ${ }^{3}$ \\ 1 Vrije Universiteit Brussel, Belgium \\ 2 EPFL, Switzerland \\ ${ }^{3}$ La Trobe University, Australia
}

\section{Erratum to: \\ R. Meersman et al. (Eds.) \\ Semantic Issues in E-Commerce Systems \\ DOI: $10.1007 / 978-0-387-35658-7$}

The book was inadvertently published with an incorrect name of the copyright holder. The name of the copyright holder for this book is: (c) IFIP International Federation for Information Processing. The book has been updated with the changes.

The updated original online version for this book can be found at DOI: $10.1007 / 978-0-387-35658-7$ 